\title{
Knowledge and practice of immediate newborn care among health care providers in eastern zone public health facilities, Tigray, Ethiopia, 2016
}

\author{
Abadi Kidanemariam Berhe ${ }^{1 *}$, Fitiwi Tinsae ${ }^{2}$ and Gebremedhin Gebreegziabher ${ }^{3}$
}

\begin{abstract}
Background: According to WHO (2013) report the number of under five-year mortality in Ethiopia was 195,504, out of this 84,437 was from neonatal death and this mortality is related to immediate obstetric and newborn care of babies provided by health care providers; But little was known about the level of knowledge and practice related to immediate newborn care and their associated factors among health care providers generally in Tigray region and specifically in the Eastern Zone so the aim of this study was to assess knowledge and practice of immediate newborn care and associated factors among health care providers in the Eastern zone public health facilities, Tigray, Ethiopia.
\end{abstract}

Methods: A cross-sectional study was conducted from December 2015 to February 2016. A total of 16 health care facilities were selected for study using simple random sampling techniques and all health care providers in the selected health care facilities who participated in immediate newborn care were involved in the study. Data were entered, cleaned and analyzed using SPSS version 20.0. Ethical clearance was obtained from Adigrat University institutional ethical review board and Tigray regional health bureau. Consent was obtained from participants to conduct the study.

Result: In this study 215 participants were contacted, with a response rate of $99.1 \%$. Generally, from the health care providers who participated in this study, $74.65 \%$ had adequate knowledge on newborn care and overall $72.77 \%$ of the participants were having good newborn care practice. Among the health care providers participated in the study, 151 (70.9\%) were getting access to newborn care national guideline and only 99 (46\%) of the health care providers get training in newborn care within the past two years before the study. Availability of national guideline, having adequate materials, the period of taking training and type of health facility were significant predictors for the health care providers newborn care practice.

Conclusion: Even though some improvement observed in the knowledge and practice of health care providers on newborn care, but still this study identified knowledge and practice gap. Regional health bureau and district health offices should provide refreshment training on immediate newborn care regularly, equipping all health facilities with necessary materials and national guideline of newborn care and there should be sharing experience between hospital and health center staffs working on newborn care through mentoring.

Keywords: Knowledge, Practice, Immediate newborn care, Tigray, Ethiopia

\footnotetext{
* Correspondence: abadik021@gmail.com

${ }^{1}$ Adigrat University, College of Medicine and Health Sciences, Adigrat,

Ethiopia

Full list of author information is available at the end of the article
} 


\section{Background}

According to WHO 2015 report globally every year, 2.7 million neonates die during the neonatal period which constitutes $45 \%$ of under- 5 mortality and approximately $58 \%$ of infant mortality and $75 \%$ of the deaths occur during the first week in the neonatal period $[1,2]$. Most neonatal deaths were in low and middle-income countries, which account for a growing proportion of all under-five mortality [3]. If the trend continues like this the share of neonatal deaths to under-five death is projected to increase from $45 \%$ in 2015 to $52 \%$ in 2030 [4]. Similarly, according to WHO (2013) report, the number of under five-year mortality in Ethiopia was 195,504, out of this 84,437 was from neonatal death [5]. According to the 2011 Ethiopia Demographic and Health Surveys (EDHS), the neonatal mortality rate was 37 per 1000 live births and the perinatal mortality rate was 46 per 1000 this is high compared to the African region average neonatal mortality rate which was 35.9 per 1000 live births [6].

A study conducted in Ethiopia on trend and determinants of neonatal mortality identified sepsis, asphyxia, birth injury, tetanus, preterm birth, congenital malformations as a cause of early neonatal mortality [7]. Immediate newborn care interventions are part of essential newborn care used to protect against newborn morbidity and mortality by using clean cord care, thermal care including drying and wrapping of the newborn immediately after delivery and delaying the newborn's first bath for at least $24 \mathrm{~h}$ or several days to reduce hypothermia risk), and initiation of breastfeeding within the first one hour of birth, management of immediate asphyxia, management of early sepsis [8]. Immediate newborn care aims at addressing poor care practices immediately following delivery [9],

Approximately 50 million were dying each year in the late 1980s, but two-thirds of this has been saved through the application of immediate newborn care [10].

Wide acknowledgments were showed that the MDG 4 target for child survival cannot be achieved without a particular focus on newborn health, especially during the first seven days of life [11]. Newborn complications resulting from hypothermia, infection, birth asphyxia and low birth weight that occurs within the first seven days following birth contribute to the highest burden of morbidity and mortality $[12,13]$.

A study conducted in Uganda among health workers practice with immediate newborn care showed that appropriate implementation is dependent upon levels of knowledge [14]. A similar study conducted in India showed a high level of knowledge among community health workers was considered as very important for improving coverage and adherence to recommended newborn care practices [15]. Other studies conducted in eastern Uganda also showed that neonatal mortality autopsies indicated the low levels of knowledge among health workers regarding prenatal and newborn care as a major determinant of death [16]. A similar study in Uganda showed that $52 \%$ of deliveries take place at the health facility, and neonatal mortality remains relatively high at 29 per 1000 live births this might be related to the immediate newborn care and obstetric care [17]. Critically ill newborn babies often present for care at the formal health facilities where general nurses and midwives are routinely deployed [18]. Studies showed that in the neonatal period more than $70 \%$ of the current deaths could be prevented through evidence-based procedures (e.g. exclusive breastfeeding and hypothermia management) [19].

Generally, Ethiopia like other countries in the subSaharan region has a high perinatal mortality and specifically the study area Tigray regional state is among the top three regional states with a high burden of perinatal mortality and second highest stillbirth from all regional states of Ethiopia according to EDHS 2011.Perinatal deaths have multi-factorial etiology, therefore, to address the high perinatal mortality there is a need for careful analysis of contributing factors in order to design appropriate interventions. Identifying the level of knowledge and practice was important for deciding the implementation strategy and for effective and sustainable implementation of knowledge into practice but only a few studies has evaluated strategies for knowledge translation in low-income countries [1]. Similarly, little is known about the level of knowledge and practice related to immediate newborn care and associated factors among health care worker providing service in intrapartum and postnatal care generally in Tigray region and specifically in Eastern Zone.

Moreover, this study will be used as a baseline data for district health office, human resource of regional health bureau to provide capacity building to health care providers based on the identified gap and used as a baseline for researchers of the further study. So, the aim of this study was to assess knowledge and practice of immediate newborn care and associated factors among health care providers in Eastern zone public health facilities, Tigray, North Ethiopia 2016.

\section{Methods}

A cross-sectional study design was conducted from December 2015 to February 2016 in Eastern zone of Tigray Region; to assess knowledge and practice of immediate newborn care and associated factors among health care providers.

According to the 2014 report of Tigray region health bureau, health service coverage in the eastern zone is approximately $80 \%$, with two general hospitals, 4 primary hospital, 26 health centers and 116 health posts. Midwives, Nurses, and public health officers are responsible 
for providing basic delivery and postnatal service both in hospitals and health centers in the study area. A total of 16 health care facilities providing delivery service (1 general hospital, 2 primary hospitals, and 13 health centers) were selected for study using simple random sampling techniques from 32 health facilities in the eastern zone, health posts were not included in the study since they did not provide delivery service. All health care providers in the selected health care facilities who participated in immediate newborn care were involved in the study.

Observational questionnaire to assess the practice of immediate newborn care and interviewer guided structured and pre-tested questionnaire to assess knowledge of newborn care on Breastfeeding, immediate postnatal care, newborn infection management, care of low birth weight baby.

Ten-degree Midwives and Nurses were recruited for data collection and two BSc degree Nurse and four masters in midwifery as a supervisor. The overall data collection process was coordinated and supervised by supervisors, co-investigators and the principal investigator.

The validity of the questionnaire was maintained by adapting the questionnaire from different relevant kinds of literature that were used by other researchers and modified in the local context. 5\% of the calculated sample size was pre-tested in another health facility which is not included in the study before the actual application for data collection. Data completeness and accuracy was checked on a daily basis by supervisors.

After the fieldwork completed and coded, then the data were entered and cleaned using SPSS version 20.0.

The data analysis methods used were descriptive analysis for frequencies, percentage, mean, standard deviation and percentage, Bivariate logistic regression analysis to see the relationship of each independent variable with practice of immediate newborn care and finally variables which are found significant at $p<0.05$ in bivariate analysis was taken to multivariate logistic regression analysis to determine the final predictors with practice of immediate newborn care.

Model assumption fulfillment and multicollinearity test were done prior to multivariate logistic regression. The final logistic model goodness of fit was assessed using the Hosmer-Lemeshow goodness of fit test, an omnibus test of model coefficients and the result shows the model is fit.

Compute score was done to assess the result of knowledge and practice of health care providers involved in the study.

There were ten procedures to assess the immediate newborn care practice on observation (see Table 2) and operationally defined as.

Good practice: if the health care providers perform more than or equal to $70 \%$ the practice procedures.
Poor practice: if the health care providers performs less than $70 \%$ of the practice procedures.

There were 12 questions to assess knowledge of health care providers' on immediate newborn care assessed using interview and operationally defined as.

Adequate knowledge: if the health care provider answers the knowledge question above or equal to mean.

Inadequate knowledge: - if the health care provider answers the knowledge questions below mean.

Finally, the result of the study was presented using tables and text.

\section{Result}

\section{Socio-demographic characteristics}

In this study 221 participants were eligible, but at the time of data collection six of the eligible study participants were not available due to office work and annual leave. Overall, among the eligible study participants, 215 were contacted, 2 interrupted between the interviews. A total of 213 participants has completed the survey, with a response rate of $99.1 \%$, out of those $150(70 \%)$ were females. The median age of the participants was 30.00 [IQR: 22-38] years. Approximately half of the participants were working in health center 116 (54.5\%) and 44 (20.7\%) of participants were trained in newborn care within the past two years. Moreover, the the majority of the participants 194 (91.1\%) were Orthodox in religion and concerning the educational status of respondents 148 (69.5\%) were diploma and 69 (29.1\%) was degree. Working experience of the participants ranges from 1 to 39 years; median 5 years [IQR 3-12 years]. Other details are shown in Table 1.

Practice of health care providers on immediate newborn care The result of this survey showed that 155 (72.8\%) of respondents generally have good newborn care practice; specifically $180(84.5 \%)$ of the participants have properly practice putting a baby on to mother's abdomen immediately after delivery, $184(86.4 \%)$ of the participants place the baby in skin-to-skin contact and on the breast to initiate breastfeeding, 156 (73.2\%) of participants apply Tetracycline eye ointment and 141 (66.2\%) give Vitamin K IM on anterior mid-thigh but only 18 (8.5\%) of participants apply chlorhexidine to cord after cord cutting (Table 2).

\section{Knowledge of health care providers on immediate newborn care}

Regarding knowledge of health care providers on option of breastfeeding of newborn $91.5 \%$ of the participants stated breastfeeding should start within one hour after delivery, 93\% choice exclusive breastfeeding for six months option, $55.9 \%$ of participants stated breastfeeding should stop completely at two years from the 
Table 1 Socio-demographic characteristics of healthcare providers in public health facilities at Eastern zone, Tigray regional state, Ethiopia, 2016

\begin{tabular}{|c|c|c|c|}
\hline Variable & & $\begin{array}{l}\text { Frequency } \\
\text { (N) }\end{array}$ & $\begin{array}{l}\text { Percent } \\
(\%)\end{array}$ \\
\hline \multirow[t]{4}{*}{ Age (in year) } & $20-30$ & 116 & 54.5 \\
\hline & $31-40$ & 71 & 33.3 \\
\hline & $41-50$ & 23 & 10.8 \\
\hline & $\geq 51$ & 3 & 1.4 \\
\hline \multirow[t]{2}{*}{ Sex } & Male & 63 & 29.6 \\
\hline & Female & 150 & 70.4 \\
\hline \multirow[t]{3}{*}{ Religion } & Orthodox & 194 & 91.1 \\
\hline & Muslim & 6 & 2.8 \\
\hline & Catholic & 13 & 6.1 \\
\hline \multirow[t]{3}{*}{ Educational status } & Diploma & 148 & 69.5 \\
\hline & Degree & 62 & 29.1 \\
\hline & MSC & 3 & 1.4 \\
\hline \multirow[t]{5}{*}{ Monthly salary(USD) } & $75-108$ & 79 & 37.1 \\
\hline & $108.10-174$ & 65 & 30.5 \\
\hline & $174.10-207$ & 41 & 19.2 \\
\hline & $207.10-240$ & 22 & 10.3 \\
\hline & $\geq 240.10$ & 6 & 2.8 \\
\hline \multirow[t]{3}{*}{ Type health facility } & General Hospital & 56 & 26.3 \\
\hline & Primary Hospital & 41 & 19.2 \\
\hline & Health Center & 116 & 54.5 \\
\hline \multirow[t]{6}{*}{ Working experience (in year) } & $1-5$ & 111 & 52.1 \\
\hline & $6-10$ & 43 & 20.2 \\
\hline & $11-15$ & 17 & 8.0 \\
\hline & $16-20$ & 16 & 7.5 \\
\hline & $21-30$ & 25 & 11.7 \\
\hline & $\geq 31$ & 1 & .5 \\
\hline
\end{tabular}

duration of breastfeeding options and $78.4 \%$ of the participants choice breastfeed more frequently as option to the care of mother with inadequate breast milk during the first few days after delivery (See Table 3).

Regarding knowledge of health care providers in the immediate postnatal care of newborn babies, $38.97 \%$ of the participants have knowledge about prevention of newborn bleeding and $41.8 \%$ have knowledge about the correct dose of Vitamin $\mathrm{K}$ to be given to a term newborn and preterm baby. In addition, the Knowledge of health care providers about infection management of newborn baby shows $35.2 \%$ of the participants know how to apply eye drops (silver nitrate) after cleaning eyes to prevent eye infections after delivery and $87.3 \%$ of the participants have knowledge about the the care of umbilical cord after delivery. Other details are shown in Table 4.

Health care providers' knowledge about the care of a low birth weight baby, $75.6 \%$ of the study participants
Table 2 Practice of health care providers on Immediate Newborn Care in public health facilities at Eastern zone, Tigray regional state, Ethiopia, 2016

\begin{tabular}{|c|c|c|c|}
\hline Variable & & $\begin{array}{l}\text { Frequency } \\
(\mathrm{N})\end{array}$ & $\begin{array}{l}\text { Percent } \\
(\%)\end{array}$ \\
\hline \multirow[t]{2}{*}{ Deliver baby on to mother's abdomen } & Yes & 180 & 84.5 \\
\hline & No & 33 & 15.5 \\
\hline \multirow{2}{*}{$\begin{array}{l}\text { Dry baby's with dry towel, Wipe eyes, } \\
\text { Wrap with dry one and cover head }\end{array}$} & Yes & 184 & 86.4 \\
\hline & No & 13 & 13.6 \\
\hline \multirow[t]{2}{*}{ Assess breathing and color } & Yes & 187 & 87.8 \\
\hline & No & 26 & 12.2 \\
\hline \multirow{2}{*}{$\begin{array}{l}\text { If the baby breath normally delay } \\
\text { cord cutting } 1-3 \mathrm{~min}\end{array}$} & Yes & 148 & 69.5 \\
\hline & No & 65 & 30.5 \\
\hline \multirow{2}{*}{$\begin{array}{l}\text { Tie the cord two fingers from abdomen and } \\
\text { another tie two fingers from the } 1 \text { st one cut } \\
\text { the cord between the } 1 \text { st \& } 2 \text { nd tie }\end{array}$} & Yes & 161 & 75.6 \\
\hline & No & 52 & 24.4 \\
\hline \multirow{2}{*}{$\begin{array}{l}\text { Place the baby in skin-to-skin contact and on } \\
\text { the breast to initiate B/feeding }\end{array}$} & Yes & 184 & 86.4 \\
\hline & No & 29 & 13.6 \\
\hline \multirow{2}{*}{$\begin{array}{l}\text { Apply chlorhexidine to cord after cord } \\
\text { cutting }\end{array}$} & Yes & 18 & 8.5 \\
\hline & No & 195 & 91.5 \\
\hline \multirow[t]{2}{*}{ Apply Tetracycline eye ointment once } & Yes & 156 & 73.2 \\
\hline & No & 57 & 26.8 \\
\hline \multirow[t]{2}{*}{ Give Vitamin K IM on anterior mid- thigh } & Yes & 141 & 66.2 \\
\hline & No & 72 & 33.8 \\
\hline \multirow[t]{2}{*}{ Weigh the baby } & Yes & 195 & 91.5 \\
\hline & No & 18 & 8.5 \\
\hline
\end{tabular}

have knowledge on ways to stabilizing the temperature of a newborn baby, $81.2 \%$ of participants have knowledge of the definition of low birth weight of newborn child and $68.5 \%$ participants stated bath more frequently as not important when taking care of a low birth weight baby. Other details are shown in Table 5 .

The overall knowledge of health care providers of Immediate Newborn Care in public health facilities of Eastern zone was $74.65 \%$.

\section{Factors that affect the practice of immediate newborn care among health care providers}

In bivariate logistic regression analysis age, sex, educational status, type of health facility, working experience, availability of national guideline, shortage of materials and the period of taking training were significant predictors but after controlling for the effects of potentially confounding variables using multivariate logistic regression only availability of national guideline, shortage of materials, the period of taking training and type of health facility were found to be significant predictors for practice of immediate newborn care. Those health facilities having adequate materials for newborn care were 4.69 times more likely practicing good newborn care 
Table 3 Knowledge of health care providers about Breastfeeding of newborn baby in public health facilities at Eastern zone, Tigray regional state, Ethiopia, 2016

\begin{tabular}{|c|c|c|c|}
\hline Variable & & $\begin{array}{l}\text { Freq. } \\
(\mathrm{N})\end{array}$ & $\begin{array}{l}\text { Percent } \\
(\%)\end{array}$ \\
\hline \multirow{5}{*}{$\begin{array}{l}\text { Initiation of breastfeeding } \\
\text { after birth }\end{array}$} & Within the first hour & 195 & 91.5 \\
\hline & $1-6 \mathrm{~h}$ after birth & 12 & 5.6 \\
\hline & $6-12 \mathrm{~h}$ & 3 & 1.4 \\
\hline & More than $12 \mathrm{~h}$ after birth, & 0.00 & 0.00 \\
\hline & Other & 3 & 1.4 \\
\hline \multirow{5}{*}{$\begin{array}{l}\text { Mother inadequate breast } \\
\text { milk during the first few } \\
\text { days after delivery }\end{array}$} & $\begin{array}{l}\text { Give formula while waiting } \\
\text { for breast milk }\end{array}$ & 19 & 8.9 \\
\hline & Breastfeed more frequently & 167 & 78.4 \\
\hline & $\begin{array}{l}\text { Give rice water, herbal } \\
\text { fluids or honey water }\end{array}$ & 8 & 3.8 \\
\hline & $\begin{array}{l}\text { Advise the mother to ask } \\
\text { someone else to breastfeed } \\
\text { her baby }\end{array}$ & 19 & 8.9 \\
\hline & Other & 0.00 & 0.00 \\
\hline \multirow{5}{*}{$\begin{array}{l}\text { Period of exclusively } \\
\text { breastfeed }\end{array}$} & 2 months & 4 & 1.9 \\
\hline & 4 month & 6 & 2.8 \\
\hline & 6 months & 200 & 93.9 \\
\hline & More than 6 months & 2 & 0.9 \\
\hline & Other & 1 & 0.5 \\
\hline \multirow{6}{*}{$\begin{array}{l}\text { After how long should a } \\
\text { mother stop breastfeeding } \\
\text { her child completely }\end{array}$} & 24 months & 119 & 55.9 \\
\hline & More than 2 years & 78 & 36.6 \\
\hline & 18 months & 12 & 5.6 \\
\hline & 6 months & 3 & 1.4 \\
\hline & 12 months & 0.00 & 0.00 \\
\hline & I have no opinion & 1 & 0.5 \\
\hline
\end{tabular}

compared to health facilities having a shortage of materials for newborn care [AOR; 4.69 95\% CI: $(1.5,14.6)]$. Similarly, facilities having a national guideline about newborn care were 28.4 times more likely practicing good newborn care than those did not have national guideline $[\mathrm{AOR}=28.495 \% \mathrm{CI}:(5.10,15.22)]$.

But those health care providers taking newborn care training before two years were $76 \%$ lower odds of newborn care practice compared to those taking training within two years $[\mathrm{AOR}=0.2495 \% \mathrm{CI}:(0.09,0.66)]$. In addition, those health care providers working in health centers were lower odds of newborn care practice compared to health care providers working in General hospitals $[\mathrm{AOR}=0.089$, $5 \%$ CI: $(0.01,0.65)]$. For detail see (Table 6).

\section{Discussion}

The first few hours since birth is the most crucial period in the life of an infant for further growth and development, which is largely determined by the quality of care that the newborn receives [20].
Table 4 Knowledge of health care providers about immediate postnatal care and Infection management of newborn baby in public health facilities at Eastern zone, Tigray regional state, Ethiopia, 2016

\begin{tabular}{|c|c|c|c|}
\hline Variable & & $\begin{array}{l}\text { Freq. } \\
(\mathrm{N})\end{array}$ & $\begin{array}{l}\text { Percent } \\
(\%)\end{array}$ \\
\hline \multirow{4}{*}{$\begin{array}{l}\text { Prevent newborn children } \\
\text { from bleeding }\end{array}$} & Breastfeeding the child, & 130 & 61.03 \\
\hline & $\begin{array}{l}\text { Not necessary to give } \\
\text { any drugs, }\end{array}$ & 0.0 & 0.00 \\
\hline & Give Vitamin K & 83 & 38.97 \\
\hline & I have no opinion, & 0.0 & 0.00 \\
\hline \multirow{7}{*}{$\begin{array}{l}\text { Dose of Vitamin } \mathrm{K} \text { to give } \\
\text { to a term newborn baby }\end{array}$} & $0.5 \mathrm{mg}$ & 102 & 47.90 \\
\hline & $1 \mathrm{mg}$ & 89 & 41.80 \\
\hline & $2 \mathrm{mg}$ & 4 & 1.90 \\
\hline & $5 \mathrm{mg}$ & 0.0 & 0.00 \\
\hline & $10 \mathrm{mg}$ & 1 & 0.50 \\
\hline & I have no opinion, & 8 & 3.80 \\
\hline & Other & 9 & 4.20 \\
\hline \multirow{6}{*}{$\begin{array}{l}\text { Prevention of eye infections } \\
\text { after delivery }\end{array}$} & Do not apply anything & 36 & 16.90 \\
\hline & $\begin{array}{l}\text { Apply breast milk in the } \\
\text { babies' eyes }\end{array}$ & 4 & 1.88 \\
\hline & $\begin{array}{l}\text { Clean eyes with sterile } \\
\text { gauze only }\end{array}$ & 83 & 38.97 \\
\hline & $\begin{array}{l}\text { Apply eye drops (silver } \\
\text { nitrate) or TTC after } \\
\text { cleaning eyes }\end{array}$ & 75 & 35.20 \\
\hline & I have no opinion & 4 & 1.88 \\
\hline & Other & 10 & 4.7 \\
\hline \multirow[t]{6}{*}{$\begin{array}{l}\text { Which care of the umbilical } \\
\text { cord of newborn after } \\
\text { delivery is important }\end{array}$} & $\begin{array}{l}\text { Cut the cord with a clean } \\
\text { instrument (for example, a } \\
\text { razor, blade) }\end{array}$ & 186 & 87.30 \\
\hline & $\begin{array}{l}\text { Use any sharp instrument } \\
\text { for cutting the cord }\end{array}$ & 7 & 3.30 \\
\hline & $\begin{array}{l}\text { After cutting the cord, } \\
\text { apply for traditional } \\
\text { herbs/medicines }\end{array}$ & 1 & 0.50 \\
\hline & $\begin{array}{l}\text { Always put a bandage } \\
\text { on the cord, }\end{array}$ & 8 & 3.80 \\
\hline & I have no opinion, & 1 & 0.50 \\
\hline & Other & 10 & 4.70 \\
\hline
\end{tabular}

In this study an effort has been made to assess knowledge, the practice of newborn care and associated factors among health care providers in public health facilities of eastern zone, Tigray, Ethiopia.

Overall, $74.65 \%$ of the health care providers participated in the study was having adequate knowledge on newborn care. This result is more or less similar to the study conducted in Addis Ababa 2013 which was 68\% [21] but it is higher than the study conducted in Egypt (52.2\%), Uganda (46.5\%), and Khartoum (50.6\%) [22]. This difference might be due to the difference in the 
Table 5 Knowledge of health care providers about Care of a low birth weight baby in public health facilities at Eastern zone, Tigray regional state, Ethiopia, 2016

\begin{tabular}{|c|c|c|c|}
\hline Variable & & $\begin{array}{l}\text { Freq. } \\
\text { (N) }\end{array}$ & Percent (\%) \\
\hline \multirow[t]{6}{*}{ Way to stabilizing the temperature of a newborn baby } & Bathing the baby in water of appropriate temperature & 6 & 2.80 \\
\hline & By putting on clothes and cover head, & 0.0 & 0.00 \\
\hline & Having the baby skin-to-skin with her/his mother, & 161 & 75.60 \\
\hline & Keep the baby in a room with a temperature of $28-30{ }^{\circ} \mathrm{C}$, & 15 & 7.00 \\
\hline & Have the baby close to heat (radiator, fire, etc.), & 31 & 14.60 \\
\hline & Other & 0.0 & 0.00 \\
\hline \multirow[t]{6}{*}{ Definition of low birth weight for newborn child } & Weight is less than $3000 \mathrm{~g}$, & 5 & 2.30 \\
\hline & Weight is less than $2500 \mathrm{~g}$, & 173 & 81.20 \\
\hline & Weight is less than $1500 \mathrm{~g}$, & 20 & 9.40 \\
\hline & Weight is less than $1000 \mathrm{~g}$ & 3 & 1.40 \\
\hline & I have no opinion, & 7 & 3.30 \\
\hline & Other & 5 & 2.30 \\
\hline \multirow[t]{6}{*}{ Not important when taking care of a low birth weight baby } & Start breastfeeding early and frequently & 36 & 16.9 \\
\hline & Bath the baby often & 146 & 68.5 \\
\hline & Keep the child warm & 13 & 6.1 \\
\hline & Apply skin to skin contact & 6 & 2.8 \\
\hline & Prevent infection from developing & 4 & 1.9 \\
\hline & None & 8 & 3.8 \\
\hline
\end{tabular}

period of study and a slight difference in the data collection tools we used.

Knowledge of breastfeeding initiation was $91.5 \%$, this finding is in line with a study conducted in Uganda which was $86.4 \%$ [13]. The findings of this study reveal that the knowledge of Exclusive breastfeeding and age of a child to stop breastfeeding are $11.2 \%$ and $9.9 \%$ respectively. This result is lower than the study conducted in Uganda (2011) which was $64 \%, 19.1 \%$ respectively [13]. This difference might be due to the difference in access to short-term training provided to health care providers on breastfeeding.

Our study showed that $71.2 \%$ of the health care providers were having knowledge on the immediate postnatal care of a newborn; compare to study conducted in Uganda which was reported $72.5 \%$ knowledge of health care provides its more or less similar finding [13]. But it is lower than the study conducted in Sudan 98\% [9], this difference might be due to the gap capacity building like in-service training on a newborn. Similarly, in this study the health care providers' knowledge of vitamin $\mathrm{K}$ was $41.8 \%$ this was more or less similar to study conducted in Uganda which was $49.7 \%$ [13]. But it is lower than the study conducted in Haryana India 76\% [23]. These variations could be largely due to the difference in the educational level of the participants and access to newborn care training provided to health care providers.

Knowledge about low birth weight management (75.6\%) among health care providers reported from this study was more or less similar to study conducted in Uganda 71\% [13].

In this study practice of newborn care among health care providers was $72.77 \%$ : this result is more or less similar to the study conducted in Vietnam (64\%) [1], Egypt (69.2\%) [20] But this finding was much higher than the study conducted in Haryana, India, Khartoum Sudan, Addis Ababa which was 55\%, 41.1\%, and 30\% respectively $[13,21,24]$. Differently, this finding was much lower than the study conducted in Tanzania which was $88.2 \%$. This difference might be due to a difference in materials, type of health facility and variation in the study period.

From the multivariate logistic regression analysis availability of national guideline was found a significant predictor of newborn care practice $[\mathrm{AOR}=28.495 \% \mathrm{CI}$ : $(5.10,15.22)]$. This result is different from Vietnam, which shows the availability of national guideline was not significantly associated with newborn care practice [1].

In addition, those health care providers working in health centers were lower odds of newborn care practice compared to health care providers working in General hospitals. This finding is different from the study conducted in Uganda, which shows the type of health facility has no significant association with newborn care practice [21].

Those health facilities having adequate materials for newborn care were 4.69 times more likely practicing good newborn care compared to health facilities having 
Table 6 Multivariate analysis to identify factors associated with Practice of health care providers on Immediate Newborn Care in public health facilities at Eastern zone, Tigray regional state, Ethiopia

\begin{tabular}{|c|c|c|c|c|}
\hline \multirow[t]{2}{*}{ Variable } & \multicolumn{2}{|c|}{ Practice of newborn care } & \multirow[t]{2}{*}{ Cured OR (95\% Cl) } & \multirow[t]{2}{*}{ Adjusted OR (95\% Cl) } \\
\hline & No N (\%) & Yes N (\%) & & \\
\hline \multicolumn{5}{|l|}{ Work experience } \\
\hline $1-5$ & $35(60.3 \%)$ & $76(49.0 \%)$ & 1.00 & 1.00 \\
\hline $6-10$ & $8(13.8 \%)$ & $35(22.6 \%)$ & $2.01(0.84,4.79)$ & $1.85(0.28,11.95)$ \\
\hline $11-15$ & $4(6.9 \%)$ & $13(8.4 \%)$ & $1.49(0.45,4.92)$ & $4.87(0.24,97.20)$ \\
\hline $16-20$ & $8(13.8 \%)$ & $8(5.2 \%)$ & $0.46(0.16,1.32)$ & $0.40(0.02,6.63)$ \\
\hline $21-30$ & $3(5.2 \%)$ & $22(14.2 \%)$ & $3.37(1.23,12.03)^{*}$ & $9.6(0.78,12.24)$ \\
\hline$\geq 31$ & $0(0.0 \%)$ & $1(0.6 \%)$ & $2.17(0.71,10.40)$ & $24.4(0.001,14.3)$ \\
\hline \multicolumn{5}{|l|}{ Age } \\
\hline $20-30$ & $24(41.4 \%)$ & 92 (59.4\%) & 1.00 & 1.00 \\
\hline $31-40$ & $28(48.3 \%)$ & $43(27.7 \%)$ & $0.40(0.20 .0 .77)^{*}$ & $0.23(0.04,1.32)$ \\
\hline $41-50$ & $6(10.3 \%)$ & $17(11.0 \%)$ & $0.73(0.26,2.07)$ & $0.21(0.01,2.71)$ \\
\hline$\geq 51$ & $0(0.0 \%)$ & $3(1.9 \%)$ & $3.80(0.63,7.23)$ & $7.29(0.001,15.1)$ \\
\hline \multicolumn{5}{|l|}{ Shortage of material } \\
\hline No & $48(82.8 \%)$ & $46(29.7 \%)$ & 1.00 & 1.00 \\
\hline Yes & $10(17.2 \%)$ & $109(70.3 \%)$ & $11.3(5.3,24.4)^{*}$ & $4.69(1.5,14.6)^{*}$ \\
\hline \multicolumn{5}{|l|}{ Guideline } \\
\hline No & $46(79.3 \%)$ & 15 (9.7\%) & 1.00 & 1.00 \\
\hline Yes & $12(20.7 \%)$ & $139(90.3 \%)$ & $35.5(15.5,81.3)^{*}$ & $28.4(5.10,39.22)^{*}$ \\
\hline \multicolumn{5}{|c|}{ When do you take training } \\
\hline Within two years & $11(28.2 \%)$ & 86 (79.6\%) & 1.00 & 1.00 \\
\hline Before two years & 28(71.8\%) & $22(20.4 \%)$ & $0.10(0.04,0.23)^{*}$ & $0.24(0.09,0.66)^{*}$ \\
\hline \multicolumn{5}{|l|}{ Education } \\
\hline Diploma & $51(87.9 \%)$ & 97 (62.6\%) & 1.00 & 1.00 \\
\hline Degree & $7(12.1 \%)$ & 55 (35.5\%) & $4.13(1.75,9.72)^{*}$ & $1.74(0.27,10.89)$ \\
\hline MSC & $0(0.0 \%)$ & $3(1.9 \%)$ & $1.9(0.67,5.24)$ & $1.04(0.04,8.23)$ \\
\hline \multicolumn{5}{|l|}{ Sex } \\
\hline Male & 10(17.2\%) & $53(34.2 \%)$ & 1.00 & 1.00 \\
\hline Female & $48(82.8 \%$ & $102(65.8 \%)$ & $0.40(0.18,0.85)^{*}$ & $0.39(0.06,2.57)$ \\
\hline \multicolumn{5}{|l|}{ Type of health } \\
\hline General hospital & $1(1.7 \%)$ & $63(40.6 \%)$ & 1.00 & 1.00 \\
\hline Primary hospital & $2(3.4 \%)$ & 57 (36.8\%) & $0.45(0.04,5.12)$ & $0.32(0.28 .3 .78)$ \\
\hline Health center & 55 (84.8\%) & $35(22.6 \%)$ & $0.01(0.001,0.76)^{*}$ & $0.08(0.01,0.65)^{*}$ \\
\hline
\end{tabular}

${ }^{*}=P \leq 0.05$ (* indicate level of significance), $1=$ Ref.cat

a shortage of materials for newborn care. This finding is consistent with the study done in Addis Ababa [21].

The odds of newborn care practice were less by $76 \%$ for those health care providers taking training before two years compared to those taking training within two years.

\section{Conclusion}

Majority health care providers in the public health facilities eastern zone of Tigray have adequate knowledge on initiation of breastfeeding, cord care, but they have a knowledge gap on prevention of eye infection and prevention and management of early bleeding. Generally, among the health care providers who participated in this study, $74.65 \%$ had adequate knowledge of newborn care.

Even though $72.77 \%$ of the participants have adequate newborn care practice, but specifically the study participants showed a gap in the practice of vitamin $\mathrm{K}$ administration and application of chlorhexidine to cord after delivery.

The health care providers practice of immediate newborn care were affected by the availability of the national 
guidelines, shortage of materials for newborn care, the time of taking training on newborn care and type of health facility.

Based on findings of the study, we recommend to Tigray regional health bureau and district health offices in collaboration with other stakeholders: to strengthen providing refreshment in-service training on immediate newborn care regularly and follow up, equipping all health facilities with national guideline of newborn care and necessary materials to provide immediate newborn care and there should be sharing experience between Hospital staffs and health centre staffs working on newborn care through mentoring.

\section{Abbreviations \\ AOR: Adjusted odd ratio; EDHS: Ethiopia demographic and health surveys; ENC: Essential newborn care; IM: Intramuscular injection; IQR: Inter quartile range; MDG: Millennium development goal; SPSS: Statistical package for social science; TTC: Tetracycline; WHO: World Health Organization}

\section{Acknowledgments}

We would like to thank Adigrat University for their financial support to carry out our research.

We would like also to extend our gratitude to eastern zone administration and respective weredas/district/health office for providing us the necessary information and cooperative support for the accomplishment of our research work.

Our gratitude also goes to data collectors and supervisors for their hard work patience in obtaining necessary information. Our special thanks also go to participants who generously shared their thoughts and feelings despite other commitments.

\section{Funding}

The source of funding to carry out for this research was Adigrat University. The funding organization has no role in the design of the study and collection, analysis, and interpretation of data and in writing the manuscript this was the role of authors.

\section{Availability of data and materials}

The datasets used and/or analyzed during this study are available from the corresponding author on reasonable request.

\section{Authors' contributions}

AK was the principal investigator who contributed to the conception and design of the study, collected, entered, analyzed, interpreted the data, prepared the manuscript and acted as the corresponding author. FT \& GG contributed to data analysis, interpretation and drafted the manuscript. All authors read and approved the final manuscript.

\section{Ethics approval and consent to participate}

Ethical approval and clearance for the study were obtained from Adigrat University institutional ethical review board and Tigray regional health bureau. An official letter of cooperation was obtained from regional health bureau to hospital and each woreda/district/health office. Verbal consent from the Medical Directors of each health centers and CEO of the hospital was obtained too.

The study participants were approached individually and given information regarding the purpose of the study, confidentiality of study, their right to participate or withdraw from the study and then finally written consent was obtained for the study.

\section{Consent for publication}

Not applicable.

\section{Competing interests}

The authors declare that they have no competing interests.

\section{Publisher's Note}

Springer Nature remains neutral with regard to jurisdictional claims in published maps and institutional affiliations.

\section{Author details}

${ }^{1}$ Adigrat University, College of Medicine and Health Sciences, Adigrat, Ethiopia. ${ }^{2}$ Department of Nursing, College of Medicine and Health Sciences, Adigrat University, Adigrat, Ethiopia. ${ }^{3}$ Department of Midwifery, College of Medicine and Health Sciences, Adigrat University, Adigrat, Ethiopia.

Received: 1 February 2017 Accepted: 29 June 2017

Published online: 11 July 2017

\section{References}

1. Leif Eriksson et al. Evidence-based practice in neonatal health: knowledge among primary health care staff in northern Viet Nam Human Resources for Health 2009, 7:36 doi:10.1186/1478-4491-7-36.

2. Level and trends of child mortality, UNICEF, WHO, UN and World bank report 2015 accessed on http://www.childmortality.org/files_v20/download/ IGME\%20report\%202015\%20child\%20mortality\%20final.pdf.

3. Kim et al. Assessing the capacity for newborn resuscitation and factors associated with providers' knowledge and skills: a cross-sectional study in Afghanistan BMC Pediatrics 2013, 13:140.

4. UNICEF, WHO, World Bank Group and UN. Levels and trends in Child mortality, 2015 report. Available at http://www.childmortality.org/files_v20/ download/igme\%20report\%202015_9_3\%20lr\%20web.pdf..

5. World health organization report on under five mortality 2013 accessed by http://apps.who.int/maternal_child_adolescent/epidemiology/profiles/ neonatal_child/eth.pdf.

6. Oestergaard MZ, Inoue M, Yoshida S, Mahanani WR, Gore FM, Cousens S, Lawn JE, Mathers CD. Neonatal mortality levels for 193 countries in 2009 with trends since 1990: a systematic analysis of progress, projections, and priorities. PLoS Med. 2011;8(8):e1001080.

7. Mekonnen et al. Neonatal mortality in Ethiopia: trends and determinants BMC Public Health 2013, 13:483.

8. WHO recommendations on ways to improve quality of newborn care in health facilities, 2016 accessd at http://www.who.int/features/2017/qualitycare-facilities/en/.

9. MahamaSaaka and Mariam Iddrisu, Patterns and Determinants of Essential Newborn Care Practices in Rural Areas of Northern Ghana International Journal of Population Research Volume 2014, Article ID 404387, 10.

10. Grant J. Opening session, world summit on medical education, Edinburgh 8-12 August, 1993. Medical Education. 1994;28(11).

11. Ganatra HA, Zaidi AK. Neonatal infections in the developing world. SeminPerinatol. 2010;34(6):416-25.

12. Shiffman J. Issue attention in global health: the case of newborn survival. Lancet. 2010;375:2045-9.

13. Ayiasi et al. Primary healthcare worker knowledge related to prenatal and immediate newborn care: a cross sectional study in Masindi, Uganda BMC Health Services Research 2014, 14:65.

14. Lutwama GW, Roos JH, Dolamo BL. A descriptive study on health workforce performance after decentralisation of health services inUganda. Hum Resour Health. 2012;10(1):41.

15. Agrawal PK, Agrawal S, Ahmed S, Darmstadt GL, Williams EK, Rosen HE, Kumar V, Kiran U, Ahuja RC, Srivastava VK, et al. Effect of knowledge of community health workers on essential newborn health care: a study from rural India. Health Policy Plan. 2012;27(2):115-26.

16. Waiswa P, Kallander K, Peterson S, Tomson G, Pariyo GW. Using the three delays model to understand why newborn babies die in eastern Uganda. Tropical Med Int Health. 2010;15(8):964-72.

17. MoH: Health Sector Strategic and Investment Plan III: Promoting People's Health to Enahnce Socio-Economic Transformation (2010/2011-2014/2015). Kampala: The Ministry of Health; 2010.

18. Rutebemberwa E, Pariyo G, Peterson S, Tomson G, Kallander K. Utilization of public or private health care providers by febrile children after user fee removal in Uganda. Malar J. 2009:8:45.

19. Darmstadt GL, Bhutta ZA, Cousens S, Adam T, Walker N, de Bernis L. Evidence-based, cost-effective interventions: how manynewborn babies can we save? Lancet. 2005;365:977-88. 
20. Neamaabd El Fattah1 and Nagwa A. Zein El Dein. Assessment of Quality of Nursing Care Provided Immediately after Birth at University Hospital in El kom-Minoufiya, Egypt. Life Science Journal. 2012; 9(4).

21. Mirkuzie et al. Current evidence on emergency obstetric and new born care services in Addis Ababa Ethiopia BMC Pregnancy and Childbirth 2014, 14:354.

22. Taha FAN. Assessment of knowledge, attitude and practices of nurse midwives towards immediate Care of the Newborn in Khartoum state teaching hospitals. 2016.

23. Louis D, Kumar P, Gupta A. Knowledge and practices of healthcare providers about essential newborn care and resuscitation in a district of Haryana. J Indian Med Assoc. 2013;111(2):114-7.

24. Deepak Louis, Praveen Kumar and Ashish Gupta. Practitioners' Series Knowledge and practices of health care providers about essential newborn care and resuscitation in a district of Haryana. J Indian Med Assoc. February 2013.vol 111(2).

Submit your next manuscript to BioMed Central and we will help you at every step:

- We accept pre-submission inquiries

- Our selector tool helps you to find the most relevant journal

- We provide round the clock customer support

- Convenient online submission

- Thorough peer review

- Inclusion in PubMed and all major indexing services

- Maximum visibility for your research

Submit your manuscript at www.biomedcentral.com/submit
Biomed Central 